\title{
Ferromagnetic ordering of linearly coordinated Co ions in $\operatorname{LiSr}_{2}\left[\mathrm{CoN}_{2}\right]$
}

\author{
T. J. Ballé, ${ }^{1}$ Z. Zangeneh, ${ }^{2}$ L. Hozoi, ${ }^{2}$ A. Jesche, ${ }^{1, *}$ and P. Höhn ${ }^{3}$ \\ ${ }^{1}$ EP VI, Center for Electronic Correlations and Magnetism, Institute of Physics, University of Augsburg, D-86159 Augsburg, Germany \\ ${ }^{2}$ Institute for Theoretical Solid State Physics, IFW Dresden, Helmholtzstr. 20, D-01069 Dresden, Germany \\ ${ }^{3}$ Max-Planck-Institut für Chemische Physik fester Stoffe, Nöthnitzer Str. 40, D-01187 Dresden, Germany
}

(Received 2 November 2018; revised manuscript received 15 February 2019; published 18 March 2019)

\begin{abstract}
$\mathrm{LiSr}_{2}\left[\mathrm{CoN}_{2}\right]$ single crystals were successfully grown out of Li-rich flux. Temperature- and field-dependent measurements of the magnetization in the range of $T=2-300 \mathrm{~K}$ and up to $\mu_{0} H=7 \mathrm{~T}$ as well as measurements of the heat capacity are presented. Ferromagnetic ordering emerges below $T_{C}=44 \mathrm{~K}$ and comparatively large coercivity fields of $\mu_{0} H=0.3 \mathrm{~T}$ as well as pronounced anisotropy are observed upon cooling. Polycrystalline samples of the $\mathrm{Ca}$ analog $\mathrm{LiCa} \mathbf{a}_{2}\left[\mathrm{CoN}_{2}\right]$ were obtained and investigated in a similar way. In both compounds Co manifests orbital contributions to the magnetic moment and large single-ion anisotropy caused by second-order spin-orbit couplings. Quantum chemistry calculations reveal a magnetic anisotropy energy of $7 \mathrm{meV}$, twice as large as the values reported for similar $\operatorname{Co} d^{8}$ systems.
\end{abstract}

DOI: 10.1103/PhysRevB.99.094422

\section{INTRODUCTION}

The formation of local magnetic moments in solids has implications that range from the design of nanoscale data storage devices to the field of massive hard magnets [1,2]. Such magnetic materials usually require the presence of heavy transition-metal or rare-earth elements in order to provide a sufficiently large magnetic anisotropy. At the origin of the desired magnetic stability is an orbital contribution to the magnetic moment. In $3 d$ transition-metal compounds, however, this contribution is normally almost fully suppressed by the crystal electric field. Few exceptions are known that are not subject to such an orbital quenching, for example: $\mathrm{LuFe}_{2} \mathrm{O}_{4}$ [3,4], NiO [5], or molecular magnets with low coordination numbers [6,7]. More recently, orbital moments, which give rise to large magnetic anisotropy, were found in the comparatively simple, inorganic materials $\mathrm{Li}_{2}\left(\mathrm{Li}_{1-x} T_{x}\right) \mathrm{N}$ with $T=\mathrm{Fe}[8,9]$ and $T=\mathrm{Mn}, \mathrm{Co}, \mathrm{Ni}[10]$ as well as in $\mathrm{Li}_{2} \mathrm{Sr}\left[\mathrm{Li}_{1-x} \mathrm{Fe}_{x} \mathrm{~N}\right]_{2}$ [11]. Similar properties are observed in linear $\mathrm{Fe}(\mathrm{I})$ [12] and $\mathrm{Co}(\mathrm{I})$ [13] complexes and were addressed by first-principles calculations [14]. The unusual presence of orbital moments in those materials is related to a rare structural motif: a linear coordination of the magnetic ion $[12,15]$. As such, the 'effective molecule' or chain is not subject to a Jahn-Teller distortion [16].

Here we present another material that contains effective linear molecules: $\mathrm{LiSr}_{2}\left[\mathrm{CoN}_{2}\right]$ with $\cdot \mathrm{N}-\mathrm{Co}-\mathrm{N}-\mathrm{Li}-\mathrm{N} \cdot$ chains running along $\langle 110\rangle$. The crystal structure is shown in Fig. 1. $\mathrm{LiSr}_{2}\left[\mathrm{CoN}_{2}\right]$ crystallizes in a tetragonal lattice with the space group $P 4_{2} / \mathrm{mnm}$. The structure is built from linear anions $\left[\mathrm{CoN}_{2}\right]^{5-}$ that are oriented perpendicular to the $c$ axis. The resulting $\cdots \mathrm{N}-\mathrm{Co}-\mathrm{N}-\mathrm{Li}-\mathrm{N} \cdots$ chains run along $\left[\begin{array}{lll}1 & 1 & 0\end{array}\right]$ and $\left[\begin{array}{ll}1 & 1\end{array}\right]$ in an alternating fashion and form layers that are separated by Sr ions.

\footnotetext{
*anton.jesche@physik.uni-augsburg.de
}

$\mathrm{LiSr}_{2}\left[\mathrm{CoN}_{2}\right]$ belongs to a series of phases with ideal composition $\mathrm{Li} A E_{2}\left[M \mathrm{~N}_{2}\right](A E=\mathrm{Ca}, M=\mathrm{Fe}$ [17]; $A E=\mathrm{Sr}$, $M=\mathrm{Co}$ [18]; $A E=\mathrm{Ca}, M=\mathrm{Cu}$ [19]) isotypic to $\alpha-\mathrm{Li}_{3}\left[\mathrm{BN}_{2}\right]$ $[20,21]$, in which $\mathrm{Li} / M$ substitution may be observed on both the $M$ [17,19] as well as the Li position [19]. Besides $\mathrm{Li} / M$ substitution, also partial occupation of the $\mathrm{Li}$ position is discussed. For $M=\mathrm{Ni}$ [22], no ordering $\mathrm{Li} / \mathrm{Ni}$ is observed, resulting in a halved unit cell $\mathrm{Ca}\left[\mathrm{Ni}_{1-x} \mathrm{Li}_{x} \mathrm{~N}\right]$ isotypic to $\mathrm{YCoC}[23]$.

The structure presents well-isolated magnetic centers of Co between two $\mathrm{N}$ atoms with a large ratio between the distance of the nearest neighbors of Co to the next-nearest neighbors of Co of approximately 1.8. The N-Co-N angle shows no deviation from $180^{\circ}$, giving rise to a linear, twofold coordination. Single crystals large enough to investigate the magnetic anisotropy of $\mathrm{LiSr}_{2}\left[\mathrm{CoN}_{2}\right]$ were grown and a thorough magnetic and structural characterization is presented, complemented by heat capacity measurements and quantum chemistry calculations. For the isoelectronic $\mathrm{LiCa}_{2}\left[\mathrm{CoN}_{2}\right]$, polycrystalline samples were obtained and characterized.

\section{METHODS}

In view of the sensitivity of the starting materials and of the reaction products to moisture and air, all manipulations associated with sample preparation and handling were performed in inert atmosphere using an Ar-filled (Praxair, $>99.999 \%$, purified with AirLiquide Oxisorb catalyst) glove box (MBraun, $p\left(\mathrm{O}_{2}\right) / p_{0}<0.1 \mathrm{ppm}, p\left(\mathrm{H}_{2} \mathrm{O}\right) / p_{0}<$ $0.1 \mathrm{ppm})$.

Laboratory powder x-ray diffraction data of selected and finely ground black crystals of both $\mathrm{LiSr}_{2}\left[\mathrm{CoN}_{2}\right]$ and $\mathrm{LiCa}_{2}\left[\mathrm{CoN}_{2}\right]$ were collected on a Huber G670 imaging plate Guinier camera $\left(2 \Theta_{\max }=100^{\circ}\right)$ using a curved germanium (111) monochromator and $\mathrm{Cu}-K_{\alpha 1}$ radiation at 293(1) K. The powder samples were placed between Kapton foils to avoid 


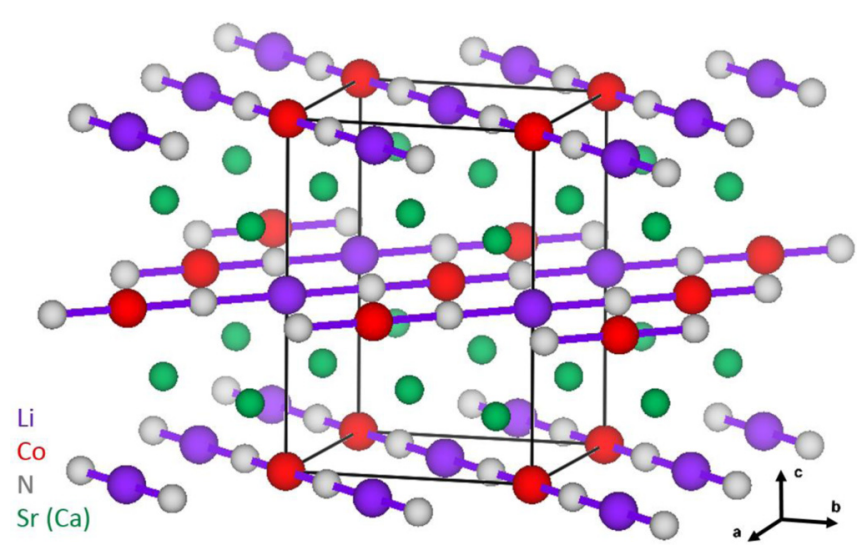

FIG. 1. Crystal structure of $\mathrm{Li}_{A E_{2}}\left[\mathrm{CoN}_{2}\right](A E=\mathrm{Sr}, \mathrm{Ca})$. The effective $\mathrm{N}-\mathrm{Co}-\mathrm{N}$ linear molecules form the basic magnetic units and are oriented along [ [ 110$]$ and [ $\left[\begin{array}{lll}1 & \overline{1} & 0\end{array}\right]$.

degradation in air. Preliminary data processing was done using the WINXPOW program package [24].

$\mathrm{X}$-ray diffraction intensity data of single crystals of both phases, $\mathrm{LiSr}_{2}\left[\mathrm{CoN}_{2}\right]$ and $\mathrm{LiCa} \mathbf{a}_{2}\left[\mathrm{CoN}_{2}\right]$, sealed in glass capillaries were collected at room temperature on a Rigaku AFC7 diffractometer equipped with a Saturn 724+ CCD area detector (Mo- $K_{\alpha}$ radiation).

Further details on the crystal structure investigations may be obtained from the Fachinformationszentrum Karlsruhe, 76344 Eggenstein-Leopoldshafen, Germany [25] on quoting the deposition numbers CCDC 1875937 and CCDC 1875936 (reevaluated) for $\mathrm{LiSr}_{2}\left[\mathrm{CoN}_{2}\right]$ and CCDC 1875935 for $\mathrm{LiCa}_{2}\left[\mathrm{CoN}_{2}\right]$, respectively.

To determine the orientation of the $\mathrm{LiSr}_{2}\left[\mathrm{CoN}_{2}\right]$ sample, Laue-back-reflection patterns were taken with a digital Dual FDI NTX camera manufactured by Photonic Science (tungsten anode, $U=20 \mathrm{kV}$ ). Chemical analysis was performed using inductively coupled plasma optical emission spectroscopy (ICP-OES, Vista-MPX). To this end, the samples were dissolved in a mixture of deionized water and dilute hydrochloric acid $(37 \%)$ in a ratio of $23: 2$. The magnetic measurements were performed using a 7 T Magnetic Property Measurement System (MPMS3 manufactured by Quantum Design), the heat capacity was measured in a $14 \mathrm{~T}$ Physical Properties Measurement System (PPMS manufactured by Quantum Design).

$A b$ initio calculations were carried out using the quantum chemistry package MOLPRO [26]. We applied all-electron Douglas-Kroll basis sets of triple- $\zeta$ quality for the Co ion [27] and all-electron triple- $\zeta$ basis functions for the two nearestneighbor nitrogen ligands [28] and the Li atoms [29]. Largecore pseudopotentials [30] were used for modeling the $\mathrm{Sr}^{2+}$ $\left(\mathrm{Ca}^{2+}\right)$ species, incorporating all occupied shells.

\section{CRYSTAL GROWTH AND BASIC STRUCTURAL CHARACTERIZATION}

$\mathrm{Li}_{3} \mathrm{~N}, \mathrm{Ca}_{3} \mathrm{~N}_{2}$, and $\mathrm{Sr}_{2} \mathrm{~N}$ were synthesized from the metallic elements (Li: Evochem, 99.9\%; Ca: Alfa Aesar, distilled dendritic pieces, 99.98\%; Sr: Alfa Aesar, distilled dendritic pieces, $99.95 \%$ ) and $\mathrm{N}_{2}$ (Praxair, $99.999 \%$, further purified by molecular sieve, $3 \AA$, Merck), the metallic elements were used without further purification. Sample preparation was carried out employing a modified high-temperature centrifugationaided filtration (HTCAF) technique [11]. The materials were filled in a Ta ampoule equipped with a strainer, welded shut, and subsequently sealed in a quartz tube [31,32]. The quartz tube was placed in a stainless steel container fitted with quartz wool and put in a box furnace. The temperature program involved heating to $1023 \mathrm{~K}$ by $100 \mathrm{Kh}^{-1}$, annealing for $2 \mathrm{~h}$ and subsequent cooling with $2 \mathrm{Kh}^{-1}$ to $723 \mathrm{~K}$ for the Ca and $823 \mathrm{~K}$ for the Sr phase, respectively. After turning the stainless steel container by $180^{\circ}$, the sample was centrifuged at $3000 \mathrm{~min}^{-1}$, removing the flux consisting mostly of lithium and further unspecified impurities.

Black agglomerates of tetragonal $\mathrm{LiCa} \mathbf{a}_{2}\left[\mathrm{CoN}_{2}\right]$ crystals up to several $\mathrm{mm}$ in size were grown from a mixture of $0.078 \mathrm{~g}$ $\mathrm{Ca}_{3} \mathrm{~N}_{2}, 0.094 \mathrm{~g}$ Co (Alfa Aesar, 99.998\%), and 0.257 g Li corresponding to a molar ratio $\mathrm{Li}: \mathrm{Ca}: \mathrm{Co}: \mathrm{N}=23: 1: 1: 0.7$.

Large single crystals of $\mathrm{LiSr}_{2}\left[\mathrm{CoN}_{2}\right]$ up to several $\mathrm{mm}$ in size and used for the magnetic investigations were grown from a mixture of $0.514 \mathrm{~g} \mathrm{Li}, 0.106 \mathrm{~g} \mathrm{Li}_{3} \mathrm{~N}, 1.600 \mathrm{~g} \mathrm{Sr}_{2} \mathrm{~N}$, and $0.127 \mathrm{~g}$ Co giving rise to a molar ratio $\mathrm{Li}: \mathrm{Sr}: \mathrm{Co}: \mathrm{N}=34: 8: 4: 5$. Both, black hexagonal $\left(\mathrm{Li}_{3} \mathrm{~N}\right)$ and tetragonal $\mathrm{LiSr}_{2}\left[\mathrm{CoN}_{2}\right]$ crystals were observed on the bottom of the ampoule after opening the Ta tube in the glove box. Powder x-ray diffraction revealed lattice parameters of $a=541.73(3) \mathrm{pm}$ and $c=$ 731.23(5) pm.

The chemical composition of two $\mathrm{LiSr}_{2}\left[\mathrm{Co}_{x} \mathrm{~N}_{2}\right]$ single crystals was determined from the ratio of $\mathrm{Li}, \mathrm{Co}$, and $\mathrm{Sr}$ by ICP-OES, assuming a fully occupied $\mathrm{Sr}$ site. The two samples show Sr:Co ratios of 2:1.02 and 2:1.01 as well as $\mathrm{Sr}: \mathrm{Li}$ ratios of 2:0.81 and 2:0.84, respectively, indicating significant $\mathrm{Li}$ vacancies.

For the isostructural $\mathrm{LiCa} 2\left[\mathrm{CoN}_{2}\right]$, three polycrystalline samples were measured and gave $\mathrm{Ca}$ :Co ratios of 2:0.93, 2:0.94, and 2:0.96, respectively. Those measurements revealed a considerable $\mathrm{Li}$ excess with $\mathrm{Ca}: \mathrm{Li}$ ratios of 2:5.07, $2: 4.39$, and 2:3.89, respectively. These are caused by Li-rich flux remnants hidden between the crystallites of the sample and not intrinsic to our crystals. Since the samples need to be fully dissolved in order to perform ICP-OES measurements, flux remnants attached to the crystallites can not be distinguished from the crystals. Therefore, only the ratio Ca:Co was used to determine the amount of Co and a fully occupied $\mathrm{Li}$ site ( $2 b$ Wyckoff site) is assumed.

Furthermore, a Laue-back-reflection pattern of $\mathrm{LiSr}_{2}\left[\mathrm{CoN}_{2}\right]$ was recorded in order to verify the orientation of the large single crystals [Fig. 2(a)]. The incident X-ray beam was oriented parallel to the $c$ axis along the surface normal of the largest facet of the crystal. The fourfold symmetry of the tetragonal structure is reflected in the measured pattern. Figure 2(b) shows a single crystal of $\mathrm{LiSr}_{2}\left[\mathrm{CoN}_{2}\right]$ on a millimeter grid.

\section{SINGLE-CRYSTAL X-RAY DIFFRACTION}

Smaller single crystals for the crystal structure determination of $\mathrm{LiSr}_{2}\left[\mathrm{CoN}_{2}\right]$ were grown from a mixture of $0.251 \mathrm{~g} \mathrm{Li}$, 


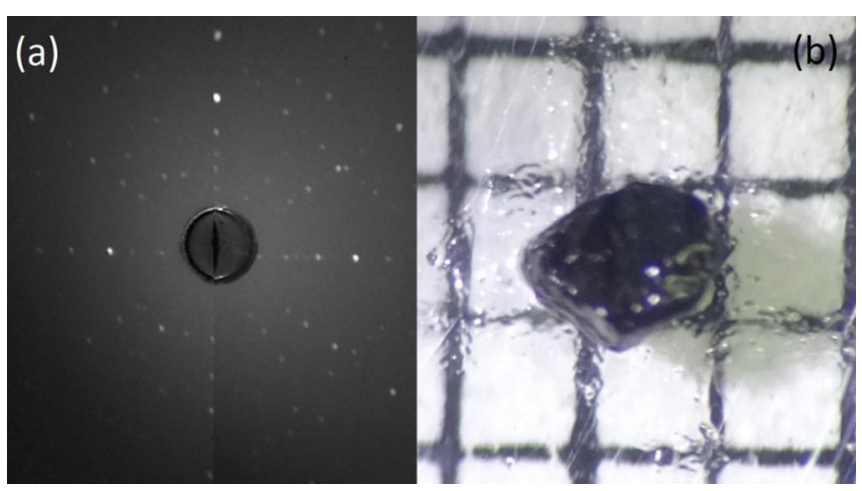

FIG. 2. (a) Laue-back-reflection pattern of $\mathrm{LiSr}_{2}\left[\mathrm{CoN}_{2}\right]$. The beam was oriented parallel to the crystallographic $c$ axis and the fourfold symmetry along the tetragonal $c$ axis is clearly visible. (b) Photo of the corresponding single crystal on a millimeter grid. The sample was embedded in vacuum grease in order to prevent oxidation.

$0.130 \mathrm{~g} \mathrm{Li}_{3} \mathrm{~N}, 0.361 \mathrm{~g} \mathrm{Sr}_{2} \mathrm{~N}$, and $0.037 \mathrm{~g}$ Co corresponding to the molar ratio $\mathrm{Li}: \mathrm{Sr}: \mathrm{Co}: \mathrm{N}=76: 9: 1: 6$. The temperature program involved heating to $923 \mathrm{~K}$ by $100 \mathrm{Kh}^{-1}$, annealing for $2 \mathrm{~h}$ and subsequent cooling with $1 \mathrm{Kh}^{-1}$ to $573 \mathrm{~K}$. $\mathrm{LiSr}_{2}\left[\mathrm{CoN}_{2}\right]$ was obtained as a side phase only. Given that structural parameters (see below) of those smaller single crystals are similar to the ones obtained for the larger single crystals (see previous section), we assume that there are no major differences (except for sample size) caused by the different temperature profile and composition of the starting materials.

The reflections of the $\mathrm{x}$-ray powder diagrams of both phases were indexed in the tetragonal system. Indexing of the single-crystal diffraction images yielded tetragonal unit cells of Laue class $4 / \mathrm{mmm}$. Systematic extinctions were identified leading to space group $P 4_{2} / \mathrm{mnm}$ (\#136) and its tetragonal subgroups $P 4_{2} n m$ (\#102) and $P \overline{4} n 2$ (\#118); all further calculations were executed in the highest-symmetry space group.

Literature data [18] were employed for the initial structural model [36], the subsequent refinement was done with the SHELXL-2018/1 software [33,34]. After several cycles of least-squares refinement and difference Fourier mapping, all atomic positions were found and all positions were refined anisotropically. Furthermore, the original single-crystal diffraction data of the 1992 publication on $\mathrm{LiSr}_{2}\left[\mathrm{CoN}_{2}\right]$ [18] was also reevaluated [36]. These crystals were prepared by annealing mixtures of $\mathrm{Li}, \mathrm{Sr}_{2} \mathrm{~N}$ and $\mathrm{Co}$ with the molar ratio 6:3:1 in nitrogen atmosphere at ambient pressure and $1123 \mathrm{~K}$ for $48 \mathrm{~h}$ and subsequent cooling to room temperature with $100 \mathrm{Kh}^{-1}$.

Crystallographic data, atomic coordinates, and isotropic thermal displacement parameters from structure refinements obtained by single-crystal $\mathrm{x}$-ray diffraction data are summarized in Tables I and II, relevant interatomic distances are listed in Table III. The refinements of the occupation parameters of all positions resulted in no significant deviations from unity in all cases. No significant deficiencies were observed in any of the crystal structures of $\mathrm{LiSr}_{2}\left[\mathrm{CoN}_{2}\right]$ and $\mathrm{LiCa} 2\left[\mathrm{CoN}_{2}\right]$; the amount of substitution $\mathrm{Co} / \mathrm{Li}$ observed
TABLE I. Selected crystal structure data and results obtained from single-crystal x-ray diffraction of $\mathrm{Li} A E_{2}\left[\mathrm{CoN}_{2}\right](A E=\mathrm{Ca}, \mathrm{Sr})$.

\begin{tabular}{|c|c|c|c|}
\hline Compound & $\mathrm{LiCa}_{2}\left[\mathrm{CoN}_{2}\right]$ & $\mathrm{LiSr}_{2}\left[\mathrm{CoN}_{2}\right]$ & $\begin{array}{c}\mathrm{LiSr}_{2}\left[\mathrm{CoN}_{2}\right] \\
\text { re-evaluated }\end{array}$ \\
\hline Space group & $P 4_{2} / m n m$ & $P 4_{2} / m n m$ & $P 4_{2} / m n m$ \\
\hline$a[\mathrm{pm}]$ & $527.87(6)$ & $543.30(17)$ & $542.4(1)$ \\
\hline$c[\mathrm{pm}]$ & $672.91(11)$ & 735.3(4) & $730.7(2)$ \\
\hline$V\left[10^{6} \mathrm{pm}^{3}\right]$ & $187.50(5)$ & $217.04(18)$ & 214.97(10) \\
\hline$Z$ & 2 & 2 & 2 \\
\hline$\lambda[\AA]$ & Mo- $K_{\alpha}$ & Мо- $K_{\alpha}$ & Мо- $K_{\alpha}$ \\
\hline$T[\mathrm{~K}]$ & 293(1) & 293(1) & 293(1) \\
\hline $2 \Theta$ Range $\left[^{\circ}\right]$ & $9.816-59.990$ & $9.330-59.75$ & $9.360-55.084$ \\
\hline$\rho\left[\mathrm{g} \mathrm{cm}^{-3}\right]$ & 3.083 & 4.118 & 4.158 \\
\hline$F(000)$ & 168 & 240 & 240 \\
\hline Refl. meas./uni. & $2223 / 169$ & $2659 / 192$ & $265 / 151$ \\
\hline Ref. parameters & 16 & 16 & 16 \\
\hline$\mu\left[\mathrm{mm}^{-1}\right]$ & 7.073 & 28.060 & 28.331 \\
\hline$\frac{R_{1}\left(F_{0}>4 \sigma\left(F_{0}\right)\right)}{R_{1}(\text { all })}$ & $0.024 / 0.025$ & $0.029 / 0.036$ & $0.035 / 0.047$ \\
\hline $\mathrm{w} R_{2} /$ GooF & $0.048 / 1.362$ & $0.069 / 1.149$ & $0.098 / 1.120$ \\
\hline $\begin{array}{l}\text { Res. } e^{-} \\
{\left[10^{-6} \mathrm{pm}^{-3}\right]}\end{array}$ & $0.463,-0.309$ & $0.992,-1.388$ & $0.862,-1.027$ \\
\hline Programs & $\begin{array}{c}\text { SHELXL }^{\mathrm{a}, \mathrm{b}} \\
\text { DIAMOND }^{\mathrm{c}}\end{array}$ & $\begin{array}{c}\text { SHELXL }^{\mathrm{a}, \mathrm{b}} \\
\text { DIAMOND }^{\mathrm{c}}\end{array}$ & $\begin{array}{c}\text { SHELXL }^{\mathrm{a}, \mathrm{b}} \\
\text { DIAMOND }^{\mathrm{c}}\end{array}$ \\
\hline
\end{tabular}

${ }^{\mathrm{a}}$ Reference [33].

${ }^{\mathrm{b}}$ Reference [34].

${ }^{\mathrm{c}}$ Reference [35].

on both the Co and Li positions is always below 5(2)\%. In other words, one of the positions between $\mathrm{N}$ neighbors $(2 a$ Wyckoff site) is almost completely occupied by Co whereas the neighboring one ( $2 b$ Wyckoff site) is merely, if at all, substituted.

TABLE II. Wyckoff positions, fractional atomic coordinates, and isotropic displacement parameters for $\operatorname{Li} A E_{2}\left[\mathrm{CoN}_{2}\right]$. The three values shown for $x, o c c$. and $U_{e q}$ correspond to $A E=\mathrm{Ca}, \mathrm{Sr}, \mathrm{Sr}$ reevaluated, respectively, see text.

\begin{tabular}{lccccll}
\hline \hline Atom & Site & $x$ & $y$ & $z$ & occ. & $U_{e q}\left[10^{4} \mathrm{pm}^{2}\right]$ \\
\hline$A E$ & $4 d$ & 0 & $1 / 2$ & $1 / 4$ & 1 & $0.0110(3)$ \\
& & & & & & $0.0115(5)$ \\
& & & & & & $0.0133(9)$ \\
$\mathrm{Co} 1$ & $2 a$ & 0 & 0 & 0 & $0.984(5)$ & $0.0097(3)$ \\
& & & & & $0.994(11)$ & $0.0118(7)$ \\
& & & & & $0.95(2)$ & $0.0112(11)$ \\
Li1 & $2 a$ & 0 & 0 & 0 & 0.016 & $0.0097(3)$ \\
& & & & & 0.006 & $0.0118(7)$ \\
& & & & & 0.05 & $0.0112(11)$ \\
$\mathrm{N}$ & $4 g$ & $0.2401(4)$ & $x$ & 0 & 1 & $0.0129(6)$ \\
& & $0.2335(5)$ & & & & $0.0169(12)$ \\
& & $0.2370(11)$ & & & & $0.015(2)$ \\
Li2 & $2 b$ & 0 & 0 & $1 / 2$ & $0.994(6)$ & $0.019(3)$ \\
& & & & & $0.974(17)$ & $0.014(7)$ \\
& & & & & $0.97(3)$ & $0.034(14)$ \\
Co2 & $2 b$ & 0 & 0 & $1 / 2$ & 0.006 & $0.019(3)$ \\
& & & & & 0.026 & $0.014(7)$ \\
& & & & & 0.03 & $0.034(14)$ \\
\hline \hline
\end{tabular}


TABLE III. Selected interatomic distances in $\mathrm{Li} A E_{2}\left[\mathrm{CoN}_{2}\right]$.

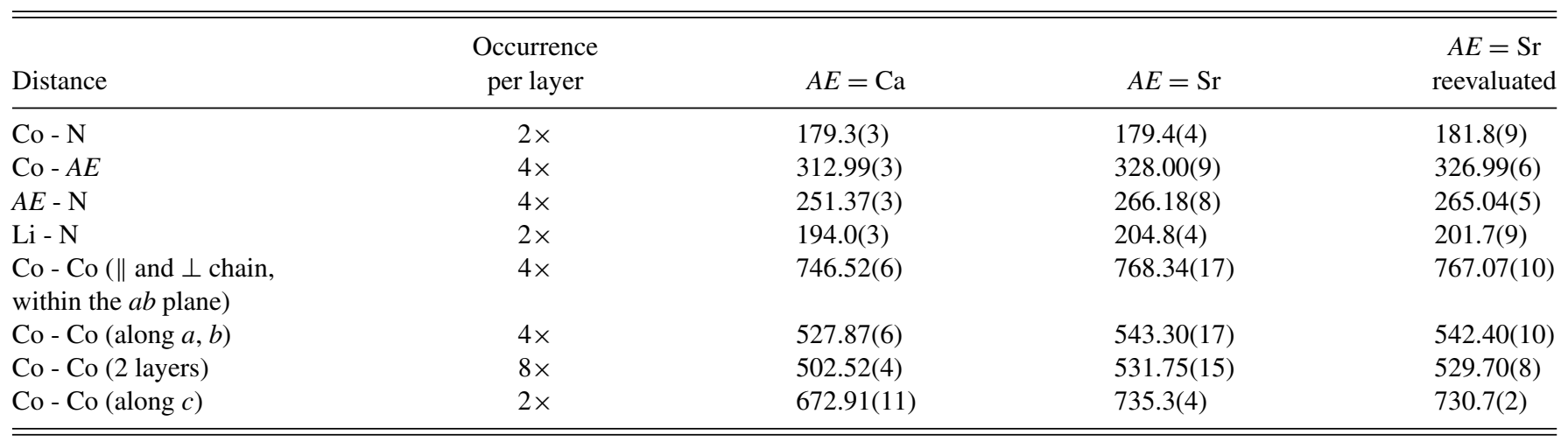

\section{MAGNETIC PROPERTIES}

Figure 3 shows the temperature-dependent magnetic susceptibility, $\chi(T)$, per mol Co for an applied field of $\mu_{0} H=$ $0.1 \mathrm{~T}$. The measurements on $\mathrm{LiSr}_{2}\left[\mathrm{CoN}_{2}\right]$ were performed with both $H \perp c$ and $H \| c$. The strong increase of $\chi(T)$ upon cooling indicates ferromagnetic ordering. A Curie temperature of $T_{\mathrm{C}}=44 \mathrm{~K}$ is inferred from the minimum in the derivative $\frac{\mathrm{d} \chi}{\mathrm{d} T}$. For polycrystalline $\mathrm{LiC} \mathbf{a}_{2}\left[\mathrm{CoN}_{2}\right]$ a Curie temperature of $T_{\mathrm{C}}=76 \mathrm{~K}$ was determined.

Figure 4 shows the inverse magnetic susceptibility, $1 /\left(\chi_{\mathrm{mol}}-\chi_{0}\right)(T)$, in a magnetic field of $\mu_{0} H=7 \mathrm{~T}$. $\mathrm{LiSr}_{2}\left[\mathrm{CoN}_{2}\right]$ follows a Curie-Weiss law above $T \sim 75 \mathrm{~K}$ with Weiss temperatures of $\Theta_{\mathrm{W}}=46 \mathrm{~K}$ and $\Theta_{\mathrm{W}}=42 \mathrm{~K}$ for $H \perp c$ and $H \| c$, respectively, in good agreement with the transition temperatures determined from $\chi(T)$. Small, but significant, deviations from Curie-Weiss behavior appear for $H \perp c$. This is reflected in the sizable, temperature-independent $\chi_{0}=2.0 \times 10^{-8} \mathrm{~m}^{3} / \mathrm{mol}_{\mathrm{Co}}$ that was also inferred from the Curie-Weiss fit. For $H \| c$, on the other hand, a smaller $\chi_{0}=-9.6 \times 10^{-10} \mathrm{~m}^{3} / \mathrm{mol}_{\mathrm{Co}}$ was obtained. The origin of the higher $\chi_{0}$ for $H \perp c$ is still unclear. Different background

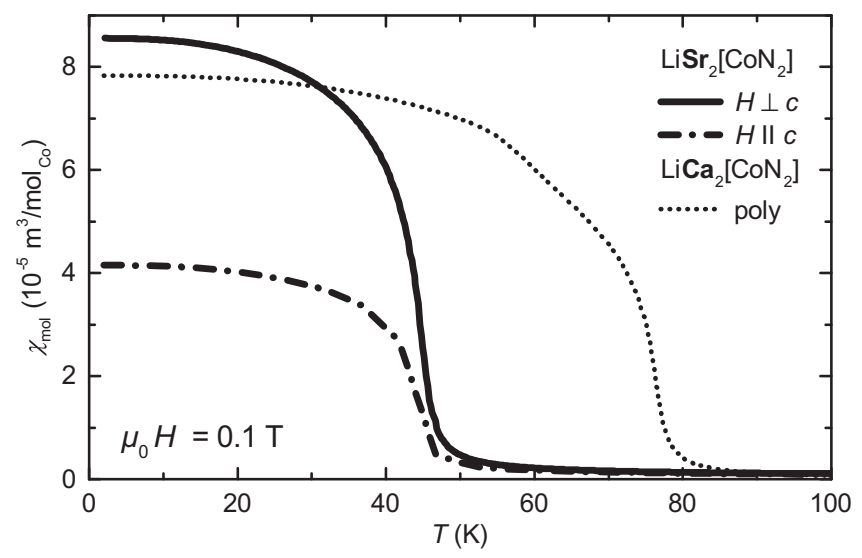

FIG. 3. Magnetic susceptibility $\chi=M / H$ per mol Co as a function of temperature for an applied magnetic field of $\mu_{0} H=0.1 \mathrm{~T}$. The solid and dashed lines show the measurements on plate-like $\mathrm{LiSr}_{2}\left[\mathrm{CoN}_{2}\right]$ with field applied perpendicular and parallel to the crystallographic $c$ axis. Ferromagnetic ordering is observed at $T_{\mathrm{C}}=$ $44 \mathrm{~K}$. The dotted line shows the measurement on polycrystalline $\mathrm{LiCa} 2\left[\mathrm{CoN}_{2}\right]$, that orders ferromagnetically at $T_{\mathrm{C}}=76 \mathrm{~K}$. contributions can be excluded. An effective moment of $\mu_{\text {eff }}=$ $3.4 \frac{\mu_{\mathrm{B}}}{\mathrm{Co}_{\mathrm{o}}}$ was determined for both directions. $\mathrm{LiCa} 2\left[\mathrm{CoN}_{2}\right]$ follows a Curie-Weiss law above $\sim 120 \mathrm{~K}$ with a ferromagnetic Weiss temperature of $\Theta_{\mathrm{W}}=78 \mathrm{~K}$ and an effective moment of $\mu_{\mathrm{eff}}=3.2 \frac{\mu_{\mathrm{B}}}{\mathrm{Co}}$.

The isothermal magnetization at $T=2 \mathrm{~K}$ in Bohr magneton per Co is shown in Fig. 5. Hysteresis emerges below the transition temperatures for both materials, in accordance with the ferromagnetic ordering inferred from $\chi(T)$. In $\mathrm{LiSr}_{2}\left[\mathrm{CoN}_{2}\right]$ a clear magnetic anisotropy is observed. Even in the vicinity of the largest available field of $\mu_{0} H=7 \mathrm{~T}$, $M(H)$ increases in a linear fashion. The coercivity fields at $T=2 \mathrm{~K}$ amount to $\mu_{0} H_{\mathrm{c}}=0.1 \mathrm{~T}$ and $\mu_{0} H_{\mathrm{c}}=0.3 \mathrm{~T}$ for $H \perp$ $c$ and $H \| c$, respectively. Both values are smaller than the coercivity field of $\mu_{0} H_{\mathrm{c}}=0.4 \mathrm{~T}$ measured in $\mathrm{LiCa}_{2}\left[\mathrm{CoN}_{2}\right]$. The changes in $M-H$ observed for $\mathrm{LiCa}_{2}\left[\mathrm{CoN}_{2}\right]$ are less steep and indicate a superposition of randomly oriented crystallites and domains, with an even higher coercivity field along the magnetically hard axis.

The influence of the Li excess mentioned in Sec. III on the magnetic properties of $\mathrm{LiCa} \mathbf{a}_{2}\left[\mathrm{CoN}_{2}\right]$ is several orders of magnitude smaller than the local moment of $\mathrm{Co}$ in our

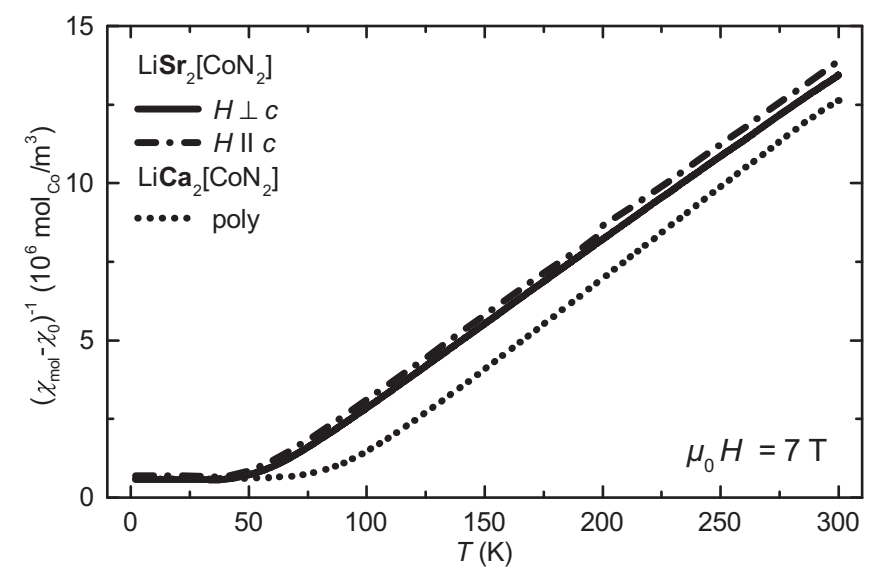

FIG. 4. Inverse magnetic susceptibility, $1 /\left(\chi_{\text {mol }}-\chi_{0}\right)(T)$, per mol Co as a function of temperature for an applied magnetic field of $\mu_{0} H=7 \mathrm{~T}$. The extracted Weiss temperatures of $\Theta_{\mathrm{W}}=46 \mathrm{~K}$ and $\Theta_{\mathrm{W}}=42 \mathrm{~K}$ for $\mathrm{LiSr}_{2}\left[\mathrm{CoN}_{2}\right]$ with $H \perp c$ and $H \| c$, respectively, are in good agreement with the $T_{\mathrm{C}}$ inferred from $\chi(T)$ in small applied fields. For polycrystalline $\mathrm{LiCa}_{2}\left[\mathrm{CoN}_{2}\right] \Theta_{\mathrm{W}}$ amounts to $78 \mathrm{~K}$. 


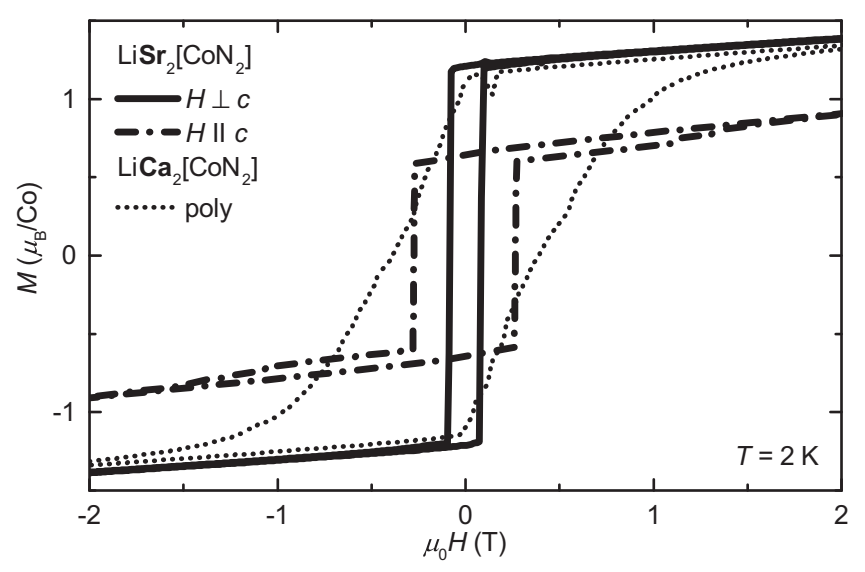

FIG. 5. Isothermal magnetization at $T=2 \mathrm{~K}$ in $\frac{\mu_{\mathrm{B}}}{\mathrm{Co}_{\mathrm{o}}}$ as a function of an applied magnetic field. The observed coercivity fields are $\mu_{0} H_{\mathrm{c}}=0.1 \mathrm{~T}$ and $\mu_{0} H_{\mathrm{c}}=0.3 \mathrm{~T}$ for $H \perp c$ and $H \| c$, respectively, for $\mathrm{LiSr}_{2}\left[\mathrm{CoN}_{2}\right]$ and $\mu_{0} H_{\mathrm{c}}=0.4 \mathrm{~T}$ for $\mathrm{LiCa}_{2}\left[\mathrm{CoN}_{2}\right]$.

sample $\left(3.5 \times 10^{-10} \mathrm{~m}^{3} \mathrm{~mol}_{\mathrm{Li}}^{-1}\right.$, see Ref. [37], compared to $7.8 \times 10^{-5} \mathrm{~m}^{3} \mathrm{~mol}_{\mathrm{Co}}^{-1}$ at $2 \mathrm{~K}$ and $0.1 \mathrm{~T}$ ). The contribution to the mass of the sample due to the Li excess can be estimated to below $10 \%$.

\section{SPECIFIC HEAT}

The specific heat in the region of the phase transition is shown in Fig. 6. A sharp, $\lambda$-like anomaly is observed at $T_{\mathrm{C}}$. The transition temperatures of $T_{\mathrm{C}}=45 \mathrm{~K}$ for $\operatorname{LiSr}_{2}\left[\mathrm{CoN}_{2}\right]$ and $T_{\mathrm{C}}=77 \mathrm{~K}$ for $\mathrm{LiCa}_{2}\left[\mathrm{CoN}_{2}\right]$ are identical to the ones estimated from the magnetic susceptibility. The entropy amounts to $1.3 \frac{\mathrm{J}}{\mathrm{molK}}$ for $\mathrm{LiSr}_{2}\left[\mathrm{CoN}_{2}\right]$ and $0.9 \frac{\mathrm{J}}{\mathrm{molK}}$ for $\mathrm{LiCa}_{2}\left[\mathrm{CoN}_{2}\right]$ at $T_{\mathrm{C}}$. In an applied field of $\mu_{0} H=7 \mathrm{~T}$ the anomaly is suppressed and entropy is shifted to higher temperatures. The measured molar entropy is significantly below the value $R \ln 2=5.76 \frac{\mathrm{J}}{\mathrm{molK}}$ that is expected for the ordering of a two-level system. Extracting the magnetic contribution,

\section{(a)}

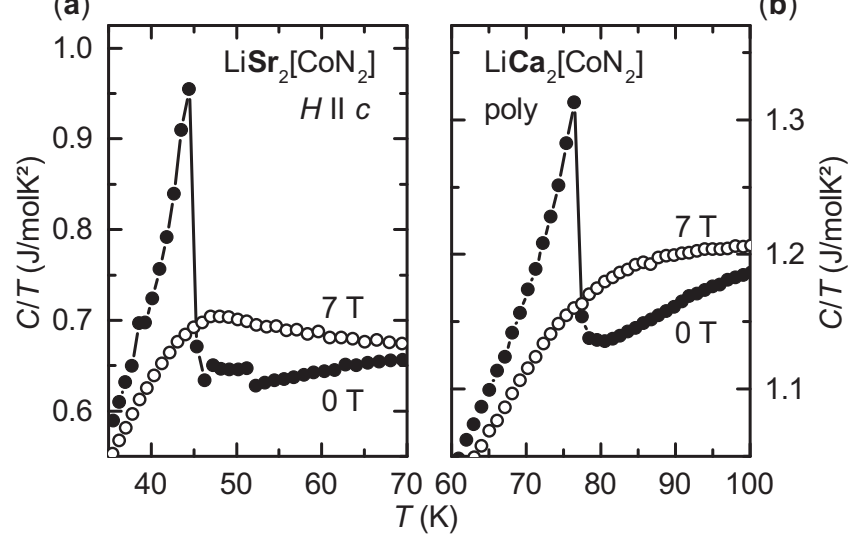

FIG. 6. Specific heat of $\mathrm{Li}_{A} E_{2}\left[\mathrm{CoN}_{2}\right]$ without (filled circles) and with an applied magnetic field of $\mu_{0} H=7 \mathrm{~T}$ (open circles). (a) $A E=\mathrm{Sr}$. The transition temperature is $T_{\mathrm{C}}=45 \mathrm{~K}$. (b) $A E=\mathrm{Ca}$. The transition occurs at $T_{\mathrm{C}}=77 \mathrm{~K}$. In both materials the peak is suppressed in an applied magnetic field of $\mu_{0} H=7 \mathrm{~T}$. as performed for the related system $\mathrm{Li}_{2}\left(\mathrm{Li}_{0.7} \mathrm{Fe}_{0.3}\right) \mathrm{N}$ [38], is not possible since the nonmagnetic reference compound $\mathrm{LiSr}_{2}\left[\mathrm{LiN}_{2}\right]$ is structurally unstable. Accordingly, the origin for the missing entropy is unclear. However, the specific heat measurements were reproduced by using additional samples. The results revealed an identical behavior with the same transition temperatures and entropies and furthermore proved well-defined Co concentrations by using an isotropic, bulk measurement.

\section{QUANTUM CHEMISTRY CALCULATIONS}

The Co $d$-shell electronic structure was analyzed on the theoretical side by $a b$ initio many-body quantum chemistry calculations. For this purpose, we used an embedded cluster defined by the $\mathrm{N}-\mathrm{Co}-\mathrm{N}$ kernel and the adjacent $\mathrm{Li}$ and alkaline-earth cations: $\left[\mathrm{CoN}_{2} \mathrm{Li}_{2} A E_{8}\right]^{13+}(A E=\mathrm{Sr}$, Ca). For convenience, in our finite-cluster calculations and subsequent analysis of the $a b$ initio results, the $\mathrm{N}-\mathrm{Co}-\mathrm{N}$ bonds are taken along the $z$ axis. Due to the rectangular arrangement of $\mathrm{Sr}$ (Ca) cations around the $\mathrm{N}-\mathrm{Co}-\mathrm{N}$ link, the actual point-group symmetry is reduced from $D_{\infty h}$ to $D_{2 h}$.

As a starting point for our computational investigation, complete-active-space self-consistent-field (CASSCF) [39] calculations were performed. We utilized an active space defined by the five $3 d$ orbitals at the Co site and eight electrons associated with the $\mathrm{Co}^{1+} 3 d^{8}$ valence configuration; to achieve a good description of the lower-energy part of the $d$ - $d$ excitation spectrum, the orbitals were optimized for an average of the lowest three triplet states. In the subsequent multireference configuration-interaction (MRCI) [39] treatment, the $\mathrm{N} 2 s, 2 p$ and Co $3 s, 3 p, 3 d$ electrons were correlated. Spin-orbit couplings (SOC's) were then accounted for according to the procedure described in Ref. [40]. The solid-state surroundings were modeled as a large array of point charges fitted to reproduce the crystal Madelung field in the cluster region [41].

We found that the low-lying $(<1 \mathrm{eV}) \mathrm{Co}^{1+} d^{8}$ states are mainly related to the $a_{1 g}^{2} e_{2 g}^{4} e_{1 g}^{2}$ and $a_{1 g}^{2} e_{2 g}^{3} e_{1 g}^{3}$ configurations, with a fully filled apical $d_{z^{2}}$ orbital. Whereas the actual symmetry of the cluster is $D_{2 h}$, we here employ, for indicating orbital occupations in a more compact form, notations corresponding to $D_{\infty h}$ point-group symmetry; the latter describes the symmetry of an isolated N-Co-N kernel. In $D_{\infty h}, d_{z^{2}}$ belongs to the $\Sigma_{g}^{+}=A_{1 g}$ irreducible representation, $\left\{d_{x y}, d_{x^{2}-y^{2}}\right\}$ to $\Lambda_{g}=E_{2 g}$, and $\left\{d_{y z}, d_{z x}\right\}$ to $\Pi_{g}=E_{1 g}$. By reducing the symmetry to $D_{2 h}$, the $D_{\infty h} E_{2 g}$ components change to $A_{g}$ $\left(d_{x^{2}-y^{2}}\right)$ and $B_{1 g}\left(d_{x y}\right)$ while the $E_{1 g}$ terms to $B_{2 g}\left(d_{x z}\right)$ and $B_{3 g}$ $\left(d_{y z}\right)$. The low-energy multiplet structure is then described in $D_{2 h}$ by the ${ }^{3} B_{1 g}$ triplet ground state and two pairs of ${ }^{3} B_{2 g},{ }^{3} B_{3 g}$ terms.

MRCI relative energies describing the excitation spectrum of a $\mathrm{Co}^{1+}$ ion in $\mathrm{LiSr}_{2}\left[\mathrm{CoN}_{2}\right]$ are listed in Table IV ( $a$ and $b$ indices are used to distinguish between states of the same symmetry and spin multiplicity in the calculations without SOC). The spin-orbit treatment was carried out in terms of all high-spin $(S=1)$ states and those low-spin $(S=0)$ components with MRCI relative energies up to $3.5 \mathrm{eV}$ (ten triplets and nine singlets). Three sets of low-energy spin-orbit states are found in the calculations: low-lying spin-orbit states 
TABLE IV. $\mathrm{Co}^{1+} 3 d$-shell electronic structure in $\mathrm{Li} A E_{2}\left[\mathrm{CoN}_{2}\right]$, as obtained by MRCI calculations. Three groups of excited states are found by spin-orbit MRCI, at $7 \mathrm{meV}, 250-450 \mathrm{meV}$, and $775-$ $880 \mathrm{meV}$. Other excited states are found above $1.95 \mathrm{eV}$ (not shown in the table). "*” denotes doubly degenerate levels.

\begin{tabular}{|c|c|c|c|c|}
\hline & & $\begin{array}{c}{ }^{3} B_{1 g} \\
\left(a_{1 g}^{2} e_{2 g}^{4} e_{1 g}^{2}\right)\end{array}$ & $\begin{array}{c}a^{3} B_{2 g}, a^{3} B_{3 g} \\
\left(a_{1 g}^{2} e_{2 g}^{3} e_{1 g}^{3}\right)\end{array}$ & $\begin{array}{c}b^{3} B_{2 g}, b^{3} B_{3 g} \\
\left(a_{1 g}^{2} e_{2 g}^{3} e_{1 g}^{3}\right)^{2}\end{array}$ \\
\hline \multirow[t]{2}{*}{$A E=\mathrm{Sr}$} & MRCI & 0 & $340 *$ & $\begin{array}{l}825 \\
830\end{array}$ \\
\hline & $\mathrm{MRCI}+\mathrm{SOC}$ & $\begin{array}{c}0 \\
7^{*}\end{array}$ & $\begin{array}{l}250^{*} \\
355^{*} \\
450^{*}\end{array}$ & $\begin{array}{c}810^{*} \\
835 \\
840 \\
870 \\
880\end{array}$ \\
\hline \multirow[t]{2}{*}{$A E=\mathrm{Ca}$} & MRCI & 0 & $320 *$ & $\begin{array}{l}775 \\
840\end{array}$ \\
\hline & $\mathrm{MRCI}+\mathrm{SOC}$ & $\begin{array}{c}0 \\
7 *\end{array}$ & $\begin{array}{l}235^{*} \\
335^{*} \\
430^{*}\end{array}$ & $\begin{array}{c}775^{*} \\
785 \\
850 \\
865 \\
875\end{array}$ \\
\hline
\end{tabular}

arising from the $a_{1 g}^{2} e_{2 g}^{4} e_{1 g}^{2}$ configuration below $10 \mathrm{meV}$ plus other states mainly arising from the $a_{1 g}^{2} e_{2 g}^{3} e_{1 g}^{3}$ configuration at $250-450$ and $810-880 \mathrm{meV}$ (see Table IV). Other excited states lie above $1.95 \mathrm{eV}$ by MRCI and are not listed in the table.

Test calculations in which only the lowest ${ }^{3} B_{1 g}$ term is included in the spin-orbit treatment yield degenerate spin-orbit states, confirming that the $a_{1 g}^{2} e_{2 g}^{4} e_{1 g}^{2}$ configuration $\left[d_{z^{2}}^{2}\left(d_{x^{2}-y^{2}} d_{x y}\right)^{4}\left(d_{x z} d_{y z}\right)^{2}\right]$ is associated with second-order SOC's $[42,43]$. In other words, the finite splitting among the ${ }^{3} B_{1 g}$ levels is the result of interactions with higher-lying states, not an intrinsic feature of the $\left[d_{z^{2}}^{2}\left(d_{x^{2}-y^{2}} d_{x y}\right)^{4}\left(d_{x z} d_{y z}\right)^{2}\right]$ configuration. Furthermore, according to Table IV the ground state is nondegenerate and the anisotropy is of easy-plane type.

Similar results are provided for the $\mathrm{LiCa}_{2}\left[\mathrm{CoN}_{2}\right]$ compound in Table IV. The main difference as compared to $\mathrm{LiSr}_{2}\left[\mathrm{CoN}_{2}\right]$ is having larger splittings within the group of $b^{3} B_{2 g}$ and $b^{3} B_{3 g}$ (related) states.

The observation of a finite amount of Li-ion vacancies in these systems led us to also consider a larger $2+$ valence state for the Co ion, since $\mathrm{Co}^{2+}$ in linear coordination shows large magnetic moments and anisotropy [44]. To investigate the $\mathrm{Co}^{2+} d^{7}$ configuration in this type of solid-state environment, we therefore performed additional embedded-cluster calculations on a $\left[\mathrm{CoN}_{2} \mathrm{Li}_{2} \mathrm{Sr}_{8}\right]^{14+}$ unit. To ensure charge neutrality, we added one (negative) electronic charge to the nearby crystalline surroundings that compensates the larger Co valence state. In particular, we equally distributed this elementary negative charge over the eight closest $\mathrm{Sr}$ atoms ( $4 b$ Wyckoff site) to the $\left[\mathrm{CoN}_{2} \mathrm{Li}_{2} \mathrm{Sr}_{8}\right]$ fragment on which the actual quantum-mechanical calculations are performed. The $D_{2 h}$ point-group symmetry at the Co site is thus preserved. First, in the CASSCF step, we optimized the orbitals for those $S=3 / 2$ quartets and $S=1 / 2$ doublets with relative energy lower than $3 \mathrm{eV}$ (ten quartets and ten doublets). Subsequently, the spin-orbit treatment was also carried out in terms of the states with MRCI relative energies up to $3 \mathrm{eV}$.

The results indicate that the ground-state configuration is $a_{1 g}^{2} e_{2 g}^{3} e_{1 g}^{2}$, with a doubly occupied $d_{z^{2}}$ orbital as for the $\mathrm{Fe}^{1+} d^{7}$ ion in $\mathrm{Li}_{3} \mathrm{~N}$ [45] and different from the $a_{1 g}^{1} e_{2 g}^{3} e_{1 g}^{3}$ non-Aufbau configuration reported recently for a $\mathrm{Co}$ (II) complex in a dialkyl complex [44]. In other words, $d_{z^{2}}$ still is the deeper level. The splitting between $d_{z^{2}}$ and $\left(d_{x y}, d_{x^{2}-y^{2}}\right)$ amounts to $870 \mathrm{meV}$ (first line in Table V) and is therefore somewhat smaller than for the $d^{7} \mathrm{~N}-\mathrm{Fe}-\mathrm{N}$ unit with $\mathrm{Li}_{3} \mathrm{~N}$ solid-state surroundings [45]. The splitting between $\left(d_{x y}, d_{x^{2}-y^{2}}\right)$ and $\left(d_{y z}, d_{z x}\right)$, on the other hand, amounts to $1.2 \mathrm{eV}$, and is somewhat larger [45]. Due to the actual $D_{2 h}$ point-group symmetry realized here, the $\left(d_{x y}, d_{x^{2}-y^{2}}\right)$ and $\left(d_{y z}, d_{z x}\right)$ single-hole states display finite splittings.

\section{DISCUSSION}

Characteristic values associated with the occurrence of magnetic ordering are summarized in Table VI. The $T_{\mathrm{C}}$ values obtained by different methods are in good agreement. For the smaller $A E=\mathrm{Ca}$, the ordering temperature almost doubles. This is considered a direct consequence of the smaller ionic radius of $\mathrm{Ca}$, that leads to a smaller separation of the onedimensional $\mathrm{N}-\mathrm{Co}-\mathrm{N}$ chains. The weaker interchain coupling for the larger $A E=\mathrm{Sr}$ yields a lower $T_{\mathrm{C}}$ in accordance with the Mermin-Wagner theorem [46], that forbids the emergence of magnetic ordering in a purely one-dimensional system.

The effective magnetic moments of roughly $3.3 \mu_{\mathrm{B}}$ per Co are enhanced when compared to the spin-only value of

TABLE V. Co $d^{7}$ electronic structure of an impuritylike $\mathrm{Co}^{2+}$ ion in $\mathrm{LiCoSr}_{2} \mathrm{~N}_{2}$, as obtained by MRCI calculations. Each MRCI+SOC value stands for a spin-orbit doublet (units of meV). The excitation from the $d_{z^{2}}$ to the $\left(d_{x y}, d_{x^{2}-y^{2}}\right)$ levels implies $\sim 900 \mathrm{meV}$; other excited states are found at 1.15-1.5 eV. Only excited states up to $2 \mathrm{eV}$ are listed. “*” denotes degenerate states.

\begin{tabular}{|c|c|c|c|c|c|}
\hline & $\begin{array}{c}{ }^{4} B_{1 g},{ }^{4} A_{g} \\
\left(a_{1 g}^{2} e_{2 g}^{3} e_{1 g}^{2}\right) \\
\end{array}$ & $\begin{array}{c}{ }^{4} B_{1 g} \\
\left(a_{1 g}^{1} e_{2 g}^{4} e_{1 g}^{2}\right)\end{array}$ & $\begin{array}{c}a^{4} B_{3 g}, a^{4} B_{2 g} \\
\left(a_{1 g}^{1} e_{2 g}^{3} e_{1 g}^{3}\right)\end{array}$ & $\begin{array}{c}b^{4} B_{2 g}, b^{4} B_{3 g} \\
\left(a_{1 g}^{1} e_{2 g}^{3} e_{1 g}^{3}\right)\end{array}$ & $\begin{array}{c}{ }^{2} B_{2 g},{ }^{2} B_{3 g} \\
\left(a_{1 g}^{2} e_{2 g}^{4} e_{1 g}^{1}\right) \\
\end{array}$ \\
\hline MRCI & $\begin{array}{c}0.00 \\
10\end{array}$ & 870 & $1210 *$ & $\begin{array}{l}1350 \\
1380\end{array}$ & $\begin{array}{l}1390 \\
1400\end{array}$ \\
\hline $\mathrm{MRCI}+\mathrm{SOC}$ & $\begin{array}{c}0.00 \\
40 \\
90 \\
130\end{array}$ & $\begin{array}{l}910 \\
920\end{array}$ & $1160-1370$ & $1390-1450$ & $1460-1500$ \\
\hline
\end{tabular}


TABLE VI. Characteristic values associated with magnetic order in $\mathrm{LiSr}_{2}\left[\mathrm{CoN}_{2}\right]$ and $\mathrm{LiCa}_{2}\left[\mathrm{CoN}_{2}\right]$. Shown are the values of $T_{\mathrm{C}}$ determined from magnetic susceptibility $(\chi)$ and specific heat at $H=0 \mathrm{~T}$ (HC) as well as the inferred Weiss temperatures $\left(\Theta_{\mathrm{W}}\right)$, effective magnetic moments $\left(\mu_{\text {eff }}\right)$, coercivity fields at $T=2 \mathrm{~K}\left(\mu_{0} H_{\mathrm{c}}\right)$, and entropy $(S)$.

\begin{tabular}{|c|c|c|c|}
\hline & $\begin{array}{c}A E=\mathrm{Sr} \\
H \| c\end{array}$ & $H \perp c$ & $\begin{array}{c}A E=\mathrm{Ca} \\
\text { poly }\end{array}$ \\
\hline$T_{\mathrm{C}}(\chi)$ & $44 \mathrm{~K}$ & $44 \mathrm{~K}$ & $76 \mathrm{~K}$ \\
\hline$T_{\mathrm{C}}(\mathrm{HC})$ & \multicolumn{2}{|c|}{$45 \mathrm{~K}$} & $77 \mathrm{~K}$ \\
\hline$\Theta_{\mathrm{W}}$ & $42 \mathrm{~K}$ & $46 \mathrm{~K}$ & $78 \mathrm{~K}$ \\
\hline$\mu_{\text {eff }}$ & $3.3 \frac{\mu_{\mathrm{B}}}{\mathrm{Co}}$ & $3.3 \frac{\mu_{\mathrm{B}}}{\mathrm{Co}_{0}}$ & $3.2 \frac{\mu_{\mathrm{B}}}{\mathrm{Co}}$ \\
\hline$\mu_{0} H_{\mathrm{c}}$ & $0.3 \mathrm{~T}$ & $0.1 \mathrm{~T}$ & $0.4 \mathrm{~T}$ \\
\hline$S\left(T_{\mathrm{C}}\right)$ & \multicolumn{2}{|c|}{$1.3 \frac{\mathrm{J}}{\mathrm{molK}}$} & $0.9 \frac{\mathrm{J}}{\mathrm{molK}}$ \\
\hline
\end{tabular}

$2.83 \mu_{\mathrm{B}}$ and indicate an orbital moment contribution. Similar values were observed in Co-doped $\mathrm{Li}_{3} \mathrm{~N}$ [10], which shows the same coordination. However, no magnetic hysteresis was observed for the latter.

The coercivity fields of $\mu_{0} H_{c}=0.3 \mathrm{~T}$ and $\mu_{0} H_{c}=0.4 \mathrm{~T}$ for $A E=\mathrm{Sr}$ and $\mathrm{Ca}$ (Fig. 5), respectively, are considered large for a $3 d$ transition-metal-based material. Similar or even larger values are only found in nanostructured systems, e.g., Co nanotubes with $\mu_{0} H_{c}=0.13 \mathrm{~T}$ at $T=5 \mathrm{~K}$ [47], surface particles in cold pressed $\mathrm{LaCoO}_{3}$ with $\mu_{0} H_{c}=1 \mathrm{~T}$ at $T=$ $5 \mathrm{~K}$ [48], and Co nanowires with $\mu_{0} H_{c}=1.1 \mathrm{~T}$ at RT [49].

$\mathrm{LiSr}_{2}\left[\mathrm{CoN}_{2}\right]$ reveals the unusual feature of the remnant moment being smaller in the direction of the broader hysteresis. Similar behavior has been observed in CeRuPO [50] and $\mathrm{CeFeAs}_{1-x} \mathrm{P}_{x} \mathrm{O}$ [51] and is attributed to a competition between single-ion anisotropy and anisotropic exchange interactions.

According to the computational data in Table IV the singleion anisotropy is indeed of easy-plane (or hard axis) type, since a singlet ground state is separated from the excited doublet state by $7 \mathrm{meV}$. This would lead to a large magnetization perpendicular to the molecule axes. Those are, however, not aligned along a unique crystallographic direction. We shall discuss possible orientations [(i)-(iii)] of the magnetically easy/hard directions and compare with the anisotropic magnetization.

(i) The easy axis is parallel to the $c$ axis, which is consistent with the concept of having orthogonal hard axes [52]. Remnant magnetization and large coercivity are indeed observed $H \| c$ (Fig. 5). However, the remnant magnetization is even larger for $H \perp c$ rendering this scenario unlikely.

(ii) Degenerate easy axes are in the $a-b$ plane oriented perpendicular to each other, to the hard axes, and to the $c$ axis. Such an orthogonal arrangement of the easy axes is, however, incompatible with the presence of ferromagnetic ordering.

(iii) A competition of ferromagnetic ordering and singleion anisotropy causes an orientation of the easy axis at a certain angle with roughly equal projections parallel and perpendicular to the $c$ axis in accordance with the observed magnetization (Fig. 5).

Since the magnetically easy axis is not only determined by the orientation of the molecule axis but also by the transition- metal valence state $[10,53]$ an alternative explanation for the high magnetization perpendicular to the $c$ axis is based on the presence of divalent cobalt. $\mathrm{Co}$ (II) is likely present within the system, arising from the Li vacancies mentioned in Sec. III ( $\approx 0.2$ per formula unit). According to Table $\mathrm{V}$ the single-ion anisotropy is then of easy-axis type and therefore perpendicular to the $c$ axis. However, for the estimated $20 \%$ $\mathrm{Co}$ (II) to cause an absolute value of the magnetic moment of $\mu_{\text {exp }}=1.38 \mu_{B}$ per Co (see Fig. 5) would require a saturation moment of roughly $1.38 \sqrt{2} / 0.2=9.8 \mu_{B}$ per Co, which is unreasonably high.

Even an itinerant scenario could account for the observed behavior: the magnetic anisotropy changes sign for an average electron count of $3 d^{7.8}$ Ref. [10]. This is consistent with the measured $\mathrm{Li}$ vacancy concentration of 0.2 per formula unit.

The measured magnetization at $T=2 \mathrm{~K}$ does not reach the spin-only value of $2 \mu_{B}$ per Co for $A E=\mathrm{Sr}$ and $\mathrm{Ca}$ (in contrast to the effective moments deduced from the hightemperature part of the susceptibility). The maximum applied field of $\mu_{0} H=7 \mathrm{~T}$ is simply not sufficient to overcome the magnetic anisotropy and the maximum projection of the ordered moment is smaller than the saturation value.

An inherent correlation seems to exist between the single-ion anisotropy and the presence of spontaneous magnetization in linearly coordinated materials: there is no hysteresis/remnant magnetization observed in the easy-plane $\mathrm{Mn}$ - and Co-doped $\mathrm{Li}_{3} \mathrm{~N}$ systems [10], which show easy axis perpendicular to the molecule axis $(\mathrm{N}-\mathrm{Mn}-\mathrm{N}$ and $\mathrm{N}-\mathrm{Co}-\mathrm{N}$, respectively). Fe-based compounds show the easy axis along the molecule axis (Fe-doped $\mathrm{Li}_{3} \mathrm{~N}$ [8] and $\mathrm{Li}_{4} \mathrm{SrN}_{2}$ [11]) and also exhibit spontaneous magnetization with comparatively large coercivity fields. However, an easy axis parallel to the molecule axis is not sufficient for the emergence of hysteresis as shown by $\mathrm{Ni}$-doped $\mathrm{Li}_{3} \mathrm{~N}$ [10].

The similarities of the magnetic properties of Fe-doped $\mathrm{Li}_{3} \mathrm{~N}$ and the title compound hold even though the origin of the spontaneous magnetization differs: $\operatorname{LiSr}_{2}\left[\mathrm{CoN}_{2}\right]$ shows a well-defined phase transition into the ordered state as evidenced by the sharp anomaly in specific heat (Fig. 6). In $\mathrm{Li}_{2}\left(\mathrm{Li}_{0.7} \mathrm{Fe}_{0.3}\right) \mathrm{N}$, on the other hand, a crossover from hightemperature paramagnetic to a slowly relaxing, seemingly static low-temperature state takes place that is driven by an enhancement of the spin relaxation times with decreasing temperature. The corresponding specific heat shows a broad Schottky anomaly [38]. In other words, Fe-doped $\mathrm{Li}_{3} \mathrm{~N}$ does not show a phase transition to a ferromagnetically ordered state as observed in $\mathrm{LiSr}_{2}\left[\mathrm{CoN}_{2}\right]$, but a crossover to a seemingly static state. At the same time the different mechanisms still manifest in spontaneous magnetization in both cases. The different behavior is not caused by the larger dilution of $\mathrm{Fe}$ in $\mathrm{Li}_{2}\left(\mathrm{Li}_{0.7} \mathrm{Fe}_{0.3}\right) \mathrm{N}$, which corresponds to a total concentration of $7.5 \% \mathrm{Fe}$ per formula unit and an average $\mathrm{Fe}-\mathrm{Fe}$ distance of $5.4 \AA$. The full Co occupation in $\mathrm{LiSr}_{2}\left[\mathrm{CoN}_{2}\right]$ leads to similar average Co-Co distances of $5.8 \AA$, however, the substitution takes place in an ordered fashion. Accordingly, we have shown that the presence of long-range magnetic interaction in the title compound, as evidenced by the sharp transition in specific heat, does not rule out the formation of orbital moments. 


\section{SUMMARY}

$\mathrm{LiSr}_{2}\left[\mathrm{CoN}_{2}\right]$ single crystals up to several millimeters along a side were obtained from a Li-rich flux. Small single crystals sufficient for $\mathrm{x}$-ray diffraction and good quality polycrystalline samples were obtained for the isostructural $\mathrm{LiCa}_{2}\left[\mathrm{CoN}_{2}\right]$ compound. The title compound orders ferromagnetically with $T_{\mathrm{C}}=45 \mathrm{~K}$ whereas a significantly enhanced $T_{\mathrm{C}}=78 \mathrm{~K}$ was found for the $\mathrm{Ca}$ analog. The magnetic anisotropy, coercivity, and effective moment are moderately enhanced and indicate the presence of an orbital contribution to the magnetic moment and large single-ion anisotropies. Although this occurs through second-order spin-orbit couplings, the resulting magnetic anisotropy energy is still large, in the region of $7 \mathrm{meV}$ according to quantum chemistry calculations. Thus we have shown another example of a linearly coordinated transition metal, different from $\mathrm{Fe}$, that exhibits orbital moment contributions and comparatively large magnetic anisotropies.

\section{ACKNOWLEDGMENTS}

The authors gratefully acknowledge L. Köhler and J. Richter for experimental help and S. Hückmann and Y. Prots for X-ray powder and single-crystal diffraction data collection. A. Mohs, A. Herrnberger, and K. Wiedenmann are acknowledged for technical support. Financial support was provided by the Deutsche Forschungsgesellschaft (DFG, German Research Foundation), Grants No. JE 748/1 and No. HO 4427/3.
[1] J. M. D. Coey, Permanent magnet applications, J. Magn. Magn. Mater. 248, 441 (2002).

[2] O. Gutfleisch, M. A. Willard, E. Brück, C. H. Chen, S. G. Sankar, and J. P. Liu, Magnetic materials and devices for the 21st century: stronger, lighter, and more energy efficient, Adv. Mater. 23, 821 (2011).

[3] J. Iida, M. Tanaka, Y. Nakagawa, S. Funahashi, N. Kimizuka, and S. Takekawa, Magnetization and spin correlation of twodimensional triangular antiferromagnet $\mathrm{LuFe}_{2} \mathrm{O}_{4}$, J. Phys. Soc. Jpn. 62, 1723 (1993).

[4] W. Wu, V. Kiryukhin, H.-J. Noh, K.-T. Ko, J.-H. Park, W. Ratcliff, P. A. Sharma, N. Harrison, Y. J. Choi, Y. Horibe, S. Lee, S. Park, H. T. Yi, C. L. Zhang, and S.-W. Cheong, Formation of Pancakelike Ising Domains and Giant Magnetic Coercivity in Ferrimagnetic $\mathrm{LuFe}_{2} \mathrm{O}_{4}$, Phys. Rev. Lett. 101, 137203 (2008).

[5] S. K. Kwon and B. I. Min, Unquenched large orbital magnetic moment in NiO, Phys. Rev. B 62, 73 (2000).

[6] J. M. Zadrozny, J. Liu, N. A. Piro, C. J. Chang, S. Hill, and J. R. Long, Slow magnetic relaxation in a pseudotetrahedral cobalt(II) complex with easy-plane anisotropy, Chem. Commun. 48, 3927 (2012).

[7] P. P. Power, Stable two-coordinate, open-shell $\left(d^{1}-d^{9}\right)$ transition metal complexes, Chem. Rev. 112, 3482 (2012).

[8] A. Jesche, R. W. McCallum, S. Thimmaiah, J. L. Jacobs, V. Taufour, A. Kreyssig, R. S. Houk, S. L. Bud'ko, and P. C. Canfield, Giant magnetic anisotropy and tunnelling of the magnetization in $\mathrm{Li}_{2}\left(\mathrm{Li}_{1-x} \mathrm{Fe}_{x}\right) \mathrm{N}$, Nat. Commun. 5, 3333 (2014).

[9] M. Fix, J. H. Atkinson, P. C. Canfield, E. del Barco, and A. Jesche, Extreme Field Sensitivity of Magnetic Tunneling in FeDoped $\mathrm{Li}_{3}$ N, Phys. Rev. Lett. 120, 147202 (2018).

[10] A. Jesche, L. Ke, J. L. Jacobs, B. Harmon, R. S. Houk, and P. C. Canfield, Alternating magnetic anisotropy of $\mathrm{Li}_{2}\left(\mathrm{Li}_{1-x} T_{x}\right) \mathrm{N}$ with $T=\mathrm{Mn}, \mathrm{Fe}, \mathrm{Co}$, and Ni, Phys. Rev. B 91, 180403(R) (2015).

[11] P. Höhn, T. J. Ballé, M. Fix, Y. Prots, and A. Jesche, Single crystal growth and anisotropic magnetic properties of $\mathrm{Li}_{2} \mathrm{Sr}\left[\mathrm{Li}_{1-x} \mathrm{Fe}_{x} \mathrm{~N}\right]_{2}$, Inorganics 4, 42 (2016).

[12] J. M. Zadrozny, D. J. Xiao, M. Atanasov, G. J. Long, F. Grandjean, F. Neese, and J. R. Long, Magnetic blocking in a linear iron(I) complex, Nat. Chem. 5, 577 (2013).
[13] Y.-S. Meng, Z. Mo, B.-W. Wang, Y.-Q. Zhang, L. Deng, and S. Gao, Observation of the single-ion magnet behavior of $\mathrm{d}^{8}$ ions on two-coordinate Co(I)-NHC complexes, Chem. Sci. 6, 7156 (2015).

[14] M. Atanasov, D. Aravena, E. Suturina, E. Bill, D. Maganas, and F. Neese, First principles approach to the electronic structure, magnetic anisotropy and spin relaxation in mononuclear $3 \mathrm{~d}-$ transition metal single molecule magnets, Coordin. Chem. Rev. 289, 177 (2015).

[15] W. M. Reiff, A. M. LaPointe, and E. H. Witten, Virtual free ion magnetism and the absence of jahn-teller distortion in a linear two-coordinate complex of high-spin iron(II), J. Am. Chem. Soc. 126, 10206 (2004).

[16] H. A. Jahn and E. Teller, Stability of polyatomic molecules in degenerate electronic states. I. Orbital degeneracy, Proc. R. Soc. London, Ser. A 161, 220 (1937).

[17] J. Klatyk and R. Kniep, Crystal structure of dicalcium (dinitridolithiate/ferrate(I)), $\mathrm{Ca}_{2}\left\{\mathrm{Li}\left[\left(\mathrm{Li}_{1-x} \mathrm{Fe}_{x}\right) \mathrm{N}_{2}\right]\right\}, x=0.82$, Z. Kristallogr. - NCS 214, 451 (1999).

[18] P. Höhn and R. Kniep, $\operatorname{LiSr}_{2}\left[\mathrm{CoN}_{2}\right]$ : A nitridocobaltate(I) with linear anions $\left[\mathrm{CoN}_{2}\right]^{5-}$, Z. Naturforsch. B 47, 434 (1992).

[19] J. Jäger and R. Kniep, Nitridocuprate(I): Quaternary phases in the systems Li-Ca/Sr-Cu-N, Z. Naturforsch. B 47, 1290 (1992).

[20] K. Cenzual, L. M. Gelato, M. Penzo, and E. Parthé, Inorganic structure types with revised space groups. I, Acta Crystallogr. B 47, 433 (1991).

[21] H. Yamane, S. Kikkawa, and M. Koizumi, High- and lowtemperature phases of lithium boron nitride, $\mathrm{Li}_{3} \mathrm{BN}_{2}$ : preparation, phase relation, crystal structure, and ionic conductivity, J. Solid State Chem. 71, 1 (1987).

[22] A. Gudat, R. Kniep, and J. Maier, $\mathrm{Ca}\left[\left(\mathrm{Ni}_{1-x} \mathrm{Li}_{x}\right) \mathrm{N}\right]$ : limited solid solutions $(0 \leqslant x \leqslant 0.58)$ in the system $\mathrm{Ca}[\mathrm{NiN}](\mathrm{Y}[\mathrm{CoC}]-$ type structure)-Ca[LiN] (modified fluorite-type structure), J. Alloy Compd. 186, 339 (1992).

[23] M. H. Gerss and W. Jeitschko, YCoC and isotypic carbides with a new, very simple structure type, Z. Naturforsch. B 41, 946 (1986).

[24] STOE WinXPOW Version 2.25, STOE \& Cie GmbH, Darmstadt, Germany (2009).

[25] Fax: (+49)7247-808-666; email: crysdata@fiz-karlsruhe.de; http://www.fiz-karlsruhe.de/request_for_deposited_data.html. 
[26] H. J. Werner, P. J. Knowles, G. Knizia, F. R. Manby, and M. Schütz, Molpro: a general-purpose quantum chemistry program package, WIREs Comput. Mol. Sci. 2, 242 (2012).

[27] N. B. Balabanov and K. A. Peterson, Systematically convergent basis sets for transition metals. I. All-electron correlation consistent basis sets for the $3 d$ elements Sc-Zn, J. Chem. Phys. 123, 064107 (2005).

[28] T. H. Dunning, Gaussian basis sets for use in correlated molecular calculations. I. The atoms boron through neon and hydrogen, J. Chem. Phys. 90, 1007 (1989).

[29] B. Prascher, D. E. Woon, K. Peterson, T. H. Dunning Jr., and A. K. Wilson, Gaussian basis sets for use in correlated molecular calculations. VII. Valence, core-valence, and scalar relativistic basis sets for $\mathrm{Li}, \mathrm{Be}, \mathrm{Na}$, and $\mathrm{Mg}$, Theor. Chem. Acc. 128, 69 (2011).

[30] P. Fuentealba, L. von Szentpaly, H. Preuss, and H. Stoll, Pseudopotential calculations for alkaline-earth atoms, J. Phys. B At. Mol. Opt. 18, 1287 (1985).

[31] P. C. Canfield, and I. R. Fisher, High-temperature solution growth of intermetallic single crystals and quasicrystals, J. Cryst. Growth 225, 155 (2001).

[32] A. Jesche and P. C. Canfield, Single crystal growth from light, volatile and reactive materials using lithium and calcium flux, Philos. Mag. 94, 2372 (2014).

[33] G. M. Sheldrick, A short history of SHELX, Acta Crytsallogr. A 64, 112 (2008).

[34] G. M. Sheldrick, Crystal structure refinement with SHELXL, Acta Crystallogr. C 71, 3 (2015).

[35] H. Putz and K. Brandenburg, Diamond - Crystal and Molecular Structure Visualization, Crystal Impact, GbR, Kreuzherrenstr. 102, 53227 Bonn, Germany, http://www.crystalimpact.com/ diamond

[36] A check of the original measuring data from 1992 revealed, that lattice parameter $a$ given in [15] should read 542.4(1) pm, instead of 524.4(1) pm. The data were refined again for this work. The distances in Ref. [15] were reported correctly.

[37] H. Lueken, Magnetische Suszeptibilität von destilliertem Lithium zwischen 294 und 3,7 K, Z. Naturforsch. A 33, 740 (1978).

[38] M. Fix, A. Jesche, S. G. Jantz, S. A. Bräuninger, H.-H. Klauss, R. S. Manna, I. M. Pietsch, H. A. Höppe, and P. C. Canfield, Ferromagnetism versus slow paramagnetic relaxation in $\mathrm{Fe}$ doped $\mathrm{Li}_{3}$ N, Phys. Rev. B 97, 064419 (2018).

[39] T. Helgaker, P. Jørgensen, and J. Olsen, Molecular ElectronicStructure Theory (Wiley, Chichester, 2000).

[40] A. Berning, M. Schweizer, H. J. Werner, P. J. Knowles, and P. Palmieri, Spin-orbit matrix elements for internally contracted multireference configuration interaction wavefunctions, Mol. Phys. 98, 1823 (2000).
[41] M. Klintenberg, S. E. Derenzo, and M. J. Weber, Accurate crystal fields for embedded cluster calculations, Comput. Phys. Commun. 131, 120 (2000).

[42] A. M. Bryan, W. A. Merrill, W. M. Reiff, J. C. Fettinger, and P. P. Power, Synthesis, structural, and magnetic characterization of linear and bent geometry cobalt(II) and nickel(II) amido complexes: Evidence of very large spin-orbit coupling effects in rigorously linear coordinated $\mathrm{Co}^{2+}$, Inorg. Chem. 51, 3366 (2012).

[43] C. G. Werncke, E. Suturina, P. C. Bunting, L. Vendier, J. R. Long, M. Atanasov, F. Neese, S. Sabo-Etienne, and S. Bontemps, Homoleptic two-coordinate silylamido complexes of chromium(I), manganese(I), and cobalt(I), Chem.-Eur. J. 22, 1668 (2016).

[44] P. C. Bunting, M. Atanasov, E. Damgaard-Møller, M. Perfetti, I. Crassee, M. Orlita, J. Overgaard, J. van Slageren, F. Neese, and J. R. Long, A linear cobalt(II) complex with maximal orbital angular momentum from a non-Aufbau ground state, Science 362, eaat7319 (2018).

[45] L. Xu, Z. Zangeneh, R. Yadav, S. Avdoshenko, J. van den Brink, A. Jesche, and L. Hozoi, Spin-reversal energy barriers of $305 \mathrm{~K}$ for $\mathrm{Fe}^{2+} \mathrm{d}^{6}$ ions with linear ligand coordination, Nanoscale $\mathbf{9}$, 10596 (2017).

[46] N. D. Mermin and H. Wagner, Absence of Ferromagnetism or Antiferromagnetism in One- or Two-Dimensional Isotropic Heisenberg Models, Phys. Rev. Lett. 17, 1133 (1966).

[47] C. P. Gräf, R. Birringer, and A. Michels, Synthesis and magnetic properties of cobalt nanocubes, Phys. Rev. B 73, 212401 (2006).

[48] J.-Q. Yan, J.-S. Zhou, and J. B. Goodenough, Ferromagnetism in $\mathrm{LaCoO}_{3}$, Phys. Rev. B 70, 014402 (2004).

[49] K. Gandha, K. Elkins, N. Poudyal, X. Liu, and J. P. Liu, High energy product developed from cobalt nanowires, Sci. Rep.-UK 4, 5345 (2014).

[50] C. Krellner and C. Geibel, Single crystal growth and anisotropy of CeRuPO, J. Cryst. Growth 310, 1875 (2008).

[51] A. Jesche, T. Förster, J. Spehling, M. Nicklas, M. de Souza, R. Gumeniuk, H. Luetkens, T. Goltz, C. Krellner, M. Lang, J. Sichelschmidt, H.-H. Klauss, and C. Geibel, Ferromagnetism and superconductivity in $\mathrm{CeFeAs}_{1-x} \mathrm{P}_{x} \mathrm{O}(0 \leqslant x \leqslant 40 \%)$, Phys. Rev. B 86, 020501(R) (2012).

[52] M. Nakano and H. Oshio, Magnetic anisotropies in paramagnetic polynuclear metal complexes, Chem. Soc. Rev. 40, 3239 (2011).

[53] L. Ke and M. van Schilfgaarde, Band-filling effect on magnetic anisotropy using a Green's function method, Phys. Rev. B 92, 014423 (2015). 